$45 \mid 2010$

Langue française, identité(s) et école(s) : le cas de la minorité catholique au Levant (milieu XIX ${ }^{\mathrm{e}}-\mathrm{XX}^{\mathrm{e}}$ siècles). Représentations identitaires et apprentissage des langues : Europe, bassin méditerranéen ( $\mathrm{XVI}{ }^{\mathrm{e}}-\mathrm{XX} \mathrm{e}^{\mathrm{e}}$ siècles)

\title{
Jean Antoine Caravolas. Jules David et les études grecques (1783-1854).
}

Préface de Luciano Canfora. Collection Études Grecques, dirigée par Renée-Paule Debaisieux. Paris : L'Harmattan, 2009, 284 pages. ISBN 978-2-296-10035-0.

Jean-Claude Chevalier

\section{(2) OpenEdition}

Édition électronique

URL : https://journals.openedition.org/dhfles/2486

DOI : $10.4000 /$ dhfles. 2486

ISSN : 2221-4038

Éditeur

Société Internationale pour l'Histoire du Français Langue Étrangère ou Seconde

Édition imprimée

Date de publication : 1 juin 2010

Pagination : 214-216

ISSN : 0992-7654

Référence électronique

Jean-Claude Chevalier, « Jean Antoine Caravolas. Jules David et les études grecques (1783-1854). ", Documents pour l'histoire du français langue étrangère ou seconde [En ligne], 45 | 2010, mis en ligne le 31 août 2013, consulté le 27 mai 2021. URL : http://journals.openedition.org/dhfles/2486 ; DOI : https:// doi.org/10.4000/dhfles.2486

Ce document a été généré automatiquement le 27 mai 2021. 


\section{Jean Antoine Caravolas. Jules David et les études grecques (1783-1854).}

Préface de Luciano Canfora. Collection Études Grecques, dirigée par Renée-Paule Debaisieux. Paris : L'Harmattan, 2009, 284 pages. ISBN 978-2-296-10035-0.

\section{Jean-Claude Chevalier}

1 Jules David est remarquable à deux égards : $1^{\circ} \mathrm{Il}$ est fils du peintre célèbre qui peignit le non moins célèbre « Les massacres de Chio »; mais lui est resté presque inconnu. $2^{\circ}$ Des mérites pourtant, et des plus curieux : il enseigna à Chio et à Smyrne, épousa une Grecque superbe qui, dit-on, devint en exil la maîtresse du roi Jérôme Napoléon à qui elle aurait donné un fils ; il fut un des premiers Français à étudier conjointement le grec ancien et le grec moderne.

2 Jean Antoine Caravolas est un spécialiste d'histoire de la pédagogie et de la linguistique ; et grec de surcroît. À ce double titre, il s'est enthousiasmé pour décrire la vie et les œuvres de Jules David. La vie surtout.

3 Jules reçoit une éducation soignée au Prytanée de Paris (actuel lycée Louis-le-Grand), puis est envoyé à Göttingen où il apprend le grec; il ébauche alors une carrière diplomatique en Italie, puis s'installe à Bruxelles où il rejoint son père, exilé comme conventionnel par le régime royal. Il revient à Paris où il se lie d'amitié avec Coray, principal représentant des lumières grecques, qui rêve d'émanciper le peuple grec et, à cette fin, entreprend de réorganiser le gymnase de Chio, en y introduisant l'enseignement mutuel, alors à la mode ; sous la direction d'un de ses disciples, Varvas. Coray sollicite Jules qui part le 24 août 1816 enseigner à Chio, en passe de devenir un collège modèle, puis à Smyrne. Le collège de Chio sera prospère jusqu'aux massacres de 1822.

4 En 1821, Jules David s'installe à Trieste au service de Jérôme Bonaparte tout en continuant à défendre la cause grecque. Enfin, il revient à Paris en 1825 et devient suppléant à la Sorbonne de l'helléniste Boissonade, mais, faute d'une agrégation, indispensable pour enseigner en faculté, il doit céder la place à Emile Egger; il se consacre alors à la rédaction d'un dictionnaire de la langue grecque. 
Philhellène avec constance, épris du grec ancien autant que moderne, Jules baigne dans la grécomanie de son époque. Fort de son séjour professionnel en Grèce, il se joint à Paris aux philhellènes, très nombreux alors. Ses activités dans les collèges grecs font sa renommée. En France, justement, l'enseignement du grec s'est développé depuis le début du XIX ${ }^{e}$ siècle; Boissonade, ami de Coray, en assure la diffusion, celle du grec ancien surtout, mais aussi celle du moderne. La diffusion était encore plus forte dans les universités allemandes; on parle même de tyrannie d'Homère, sous l'influence de Johann Gesner, puis de Heyne à Göttingen. Les frères Schlegel et Humboldt se distinguent comme animateurs du développement du grec.

6 Jules David se situe dans ce mouvement. Il s'est entraîné au grec moderne, à Chio et à Smyrne, il a confronté l'hellenike et la romaike et écrit en 1820 un Parallèle des deux langues grecques,ancienne et moderne, pensant faire cuvre de novateur quand il soulignait les ressemblances. Ouvrage suivi d'un autre manuel, rédigé en français: Méthode pour étudier la langue grecque moderne (1821, réédité en 1828). Ce gros ouvrage comporte quatorze pages de dialogues qui évoquent la vie grecque, accompagnant dixhuit brefs chapitres de syntaxe. Travaux qui seront repris par la suite, par exemple dans la Grammaire grecque d'Émile Legrand qui en copie des passages entiers. Le Parallèle sera même traduit en allemand.

7 Installé en France, Jules David se consacre entièrement désormais à une tâche nouvelle: la rédaction d'un dictionnaire qui confronte le grec littéraire au français moderne ; l'ouvrage tient compte, mais secondairement, du grec moderne. Travail qui trouve sur son chemin le Dictionnaire franco-grec de Planche, Alexandre et Defaucompret, en sorte que celui de J. David ne sera jamais édité, malgré des demandes répétées de subventions.

Personnage curieux que ce Jules David; non moins curieux et vivant l'ouvrage que lui consacre Jean Antoine Caravolas. De multiples recherches et enquêtes originales sont accumulées, parfois dans le désordre et dans les répétitions, à l'image le plus souvent de la vie de Jules David. Mais c'est un travail de défrichage qui apportera beaucoup au lecteur patient.

\section{AUTEUR}

\section{JEAN-CLAUDE CHEVALIER}

Université Paris 8 